Universidad de Lima

Facultad de Ciencias Empresariales y Económicas

Carrera de Economía

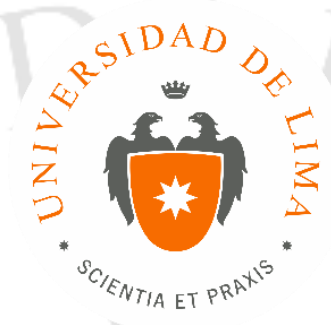

\title{
ANÁLISIS DE LAS PRINCIPALES METODOLOGÍAS DE CLASIFICACIÓN DE RIESGOS PARA LA EVALUACIÓN DE EMPRESAS EN EL PERÚ
}

Trabajo de suficiencia profesional para optar el Título Profesional de Economista

Sustentación de caso

\section{Patrick Alfred Guimac Wong}

Código 20070487

\section{Asesor}

Pavel Omar Hernández Bracamonte

$$
\text { Lima-Perú }
$$

Diciembre de 2018 


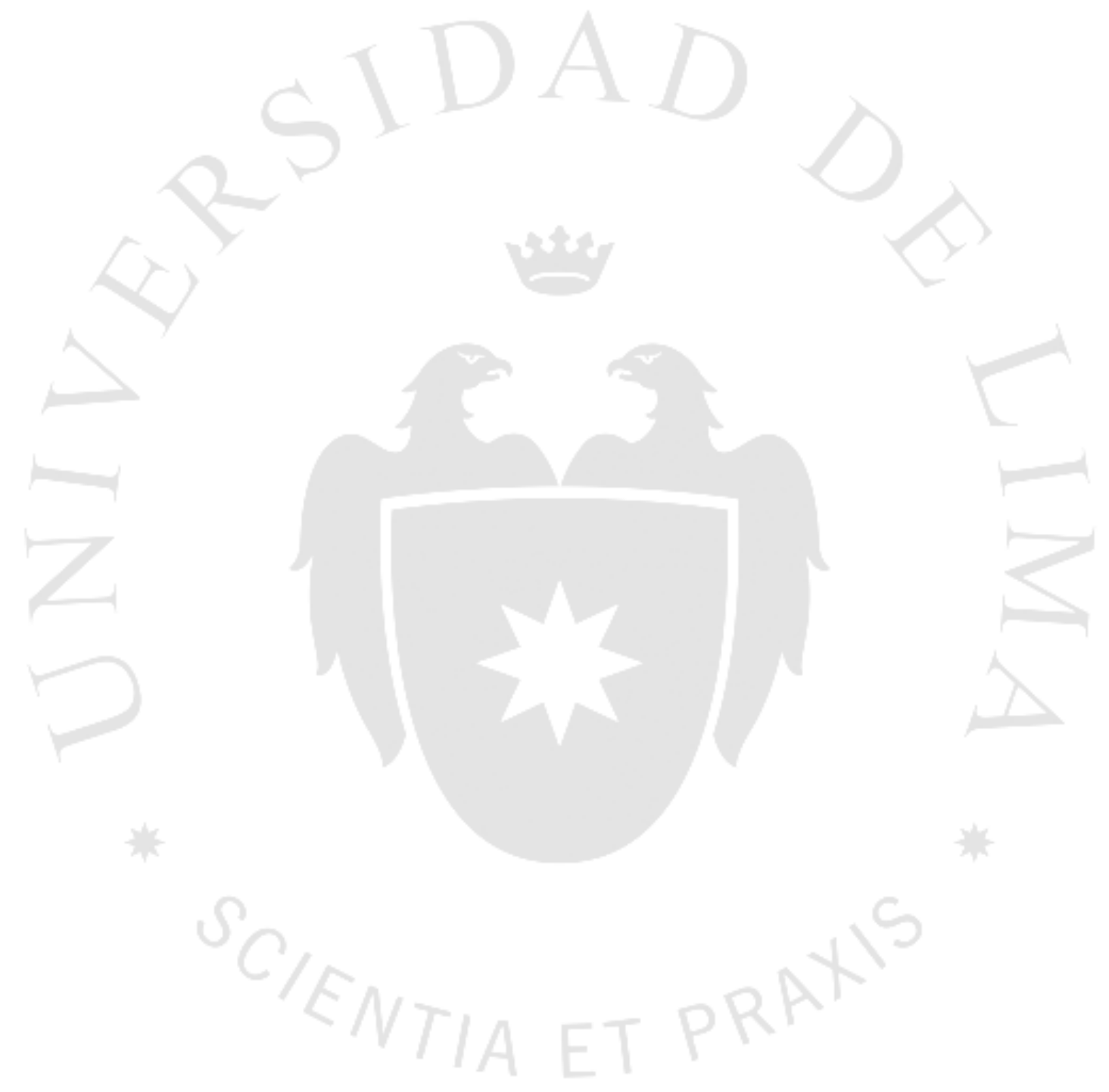




\section{ANÁLISIS DE LAS PRINCIPALES METODOLOGÍAS DE CLASIFICACIÓN DE RIESGOS PARA LA EVALUACIÓN DE EMPRESAS EN EL PERÚ}




\section{TABLA DE CONTENIDO}

1. INTRODUCCIÓN ..........................................................................................................1

2. OBJETIVOS........................................................................................................

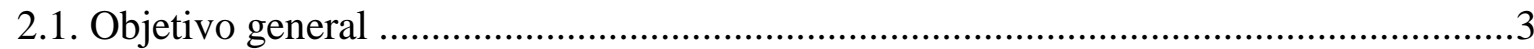

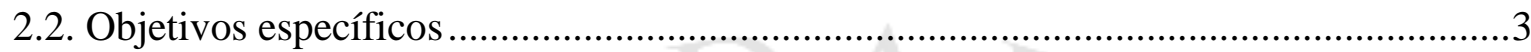

3. PREGUNTAS DE INVESTIGACIÓN .......................................................................4

4. METODOLOGÍA DE RECOLECCIÓN DE LA INFORMACIÓN..............................5

5. METODOLOGÍA DE ANÁLISIS DE LA INFORMACIÓN ....................................6

6. DESCRIPCIÓN DE CASO...........................................................................................7

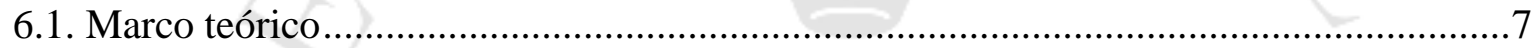

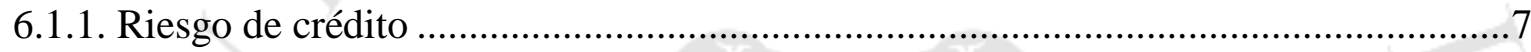

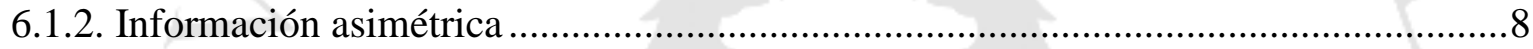

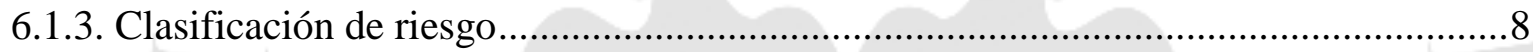

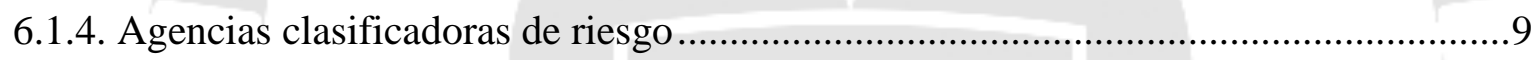

6.2. Recolección y transformación de datos de los procesos y metodologías para la

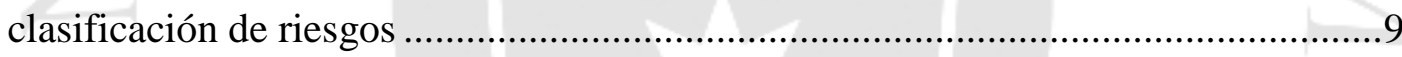

6.2.1. Proceso y metodologías en las agencias clasificadoras ..........................................10

6.2.2. Proceso y metodologías en los bancos del sistema financiero peruano ......................12

7. ANÁLISIS Y DISCUSIÓN DE RESULTADOS..............................................................18

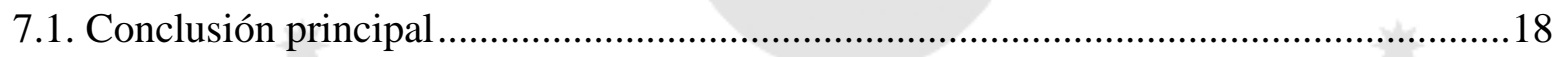

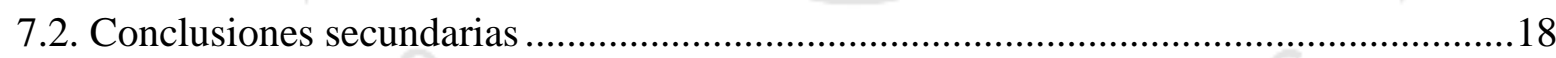

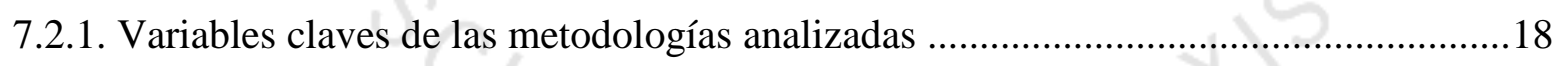

7.2.2. Principales diferencias en las metodologías analizadas .........................................18

7.2.3. Principales diferencias en los procesos metodológicos ............................................20

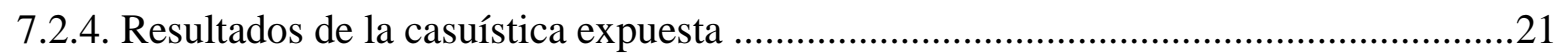

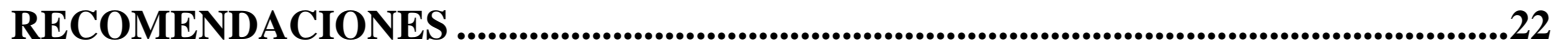

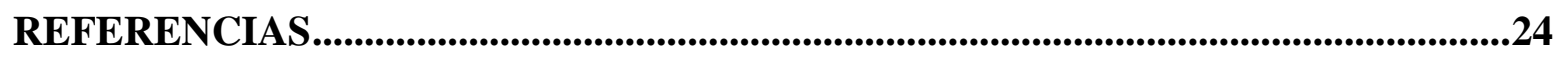

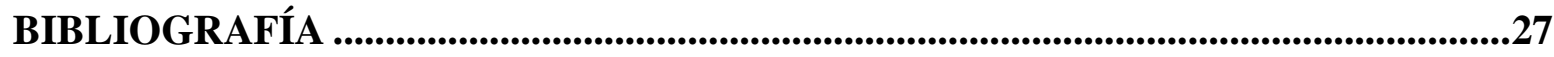




\section{ÍNDICE DE TABLAS}

Tabla 6.1 Proceso de clasificación y políticas de difusión de las agencias clasificadoras 10

Tabla 6.2 Metodología de evaluación de riesgos de las empresas clasificadoras peruanas 12

Tabla 6.3 Proceso crediticio para la evaluación de riesgos de las entidades bancarias en el Perú 13

Tabla 6.4 Metodología empleada para la evaluación de riesgos de las entidades bancarias.

Tabla 6.5 Cuadro comparativo resumen de las metodologías de evaluación de riesgos 16 Tabla 6.6 Casuística comparativa de las metodologías analizadas..... 17
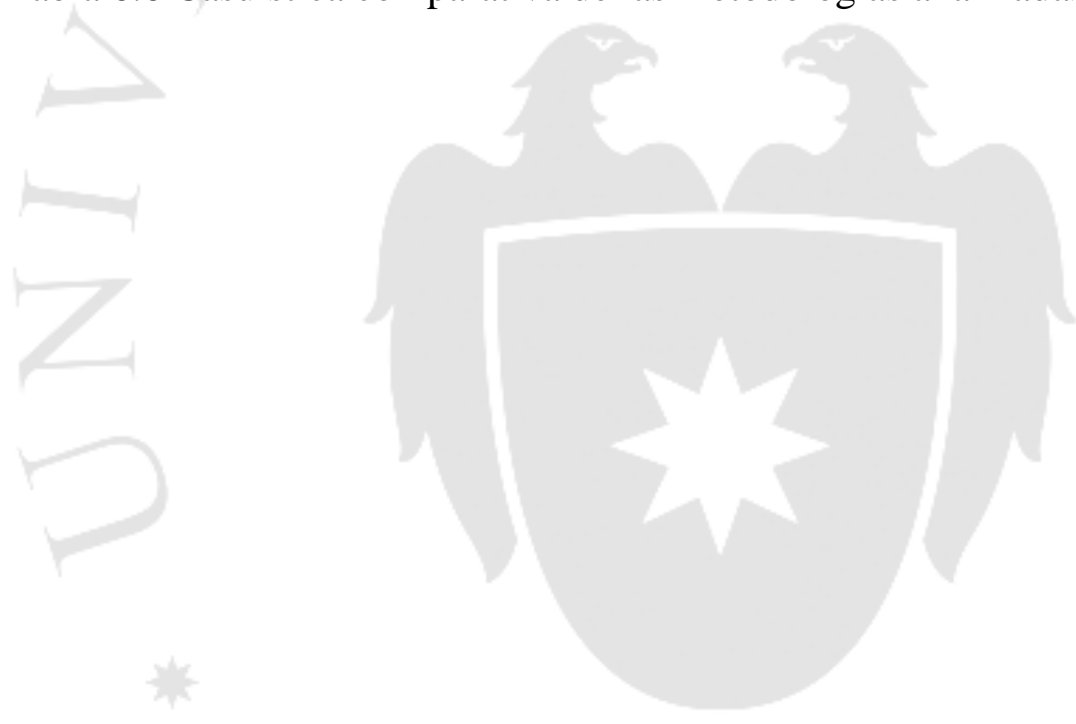


\section{ÍNDICE DE ANEXOS}

Anexo 1: Empresas clasificadoras de riesgo en el Perú................................................29

Anexo 2: Participación de mercado de las empresas clasificadoras en el Perú ................31

Anexo 3: Simbología de las empresas clasificadoras de riesgo..................................... 32

Anexo 4: Comité de Supervisión Bancaria de Basilea (CSBB) ...................................... 33 


\section{INTRODUCCIÓN}

El estallido de la burbuja inmobiliaria en Estados Unidos en el 2007 acarreó una importante crisis económica a nivel mundial, tomando como base y detonante el riesgo de crédito (riesgo de crédito asociado a las hipotecas subprime); este hecho demostró serios problemas en la concepción del riesgo y la vulnerabilidad del sistema financiero.

La gravedad de esta crisis no solo afectó al sistema financiero estadounidense, provocando la bancarrota de grandes fondos de inversión, de bancos, de empresas aseguradoras y de empresas evaluadoras de riesgo; sino también contagió al sistema financiero internacional, el cual redujo los créditos, generando un riesgo de liquidez, trayendo consigo un declive en los ciclos económicos, crisis bursátiles y tensiones inflacionarias, todo ello traduciéndose en la crisis financiera del 2008 (Parodi, 2012).

Se debe señalar que el riesgo de crédito es el más 'sistémico' de todos, es decir, el que más problemas puede crear en una economía, por la máxima interconectividad con los jugadores (del sector financiero y no financiero) y el sector real, siendo innegable además mencionar que toda transacción financiera se encuentra expuesta a este riesgo; naciendo ahí la importancia de su correcta gestión (Belaunde, 2012).

Ante ello el mercado encuentra en las clasificaciones de riesgos otorgadas por las agencias clasificadoras una herramienta para la identificación de riesgos, que de una manera objetiva permiten reflejar el riesgo crediticio del prestamista o instrumento, brindando información suficiente para la toma de decisiones.

Por su lado, los bancos en el sistema financiero, al contar con el riesgo de crédito implícito en la propia gestión de su actividad, realizan sus propias mediciones metodológicas con el fin de identificar este mismo riesgo.

Si bien ambas metodologías mantienen un mismo fin, es posible que dadas las diferentes variables usadas en sus modelos, de acuerdo a su experiencia y a la propia asimetría de la información que se obtengan diferentes resultados.

El presente trabajo analiza y describe los diversos modelos de clasificación de riesgos, detallando además las diversas metodologías empleadas, realizadas por empresas financieras y empresas clasificadoras de riesgos, con el fin de medir, mitigar y compartir 
las buenas prácticas realizadas, definiendo variables cuantitativas y cualitativas críticas a considerar en un proceso de gestión del riesgo de crédito.

El trabajo se encuentra dividido en siete capítulos. El primero y el segundo nos muestran nuestros objetivos y preguntas de investigación del caso de estudio en el marco peruano; el tercero y cuarto capítulo también descriptivos, nos detallan los procesos metodológicos empleados para la obtención de información y preparación de datos necesarios para el estudio del caso. Por otro lado, en el quinto capítulo se intenta mostrar un panorama completo del mundo de las clasificaciones de riesgos entre las clasificaciones de las entidades bancarias y las agencias clasificadoras de riesgo; adentrando en teorías y conceptos básicos, así como también en su normativa y regulación, para posteriormente entender los procesos y metodologías empleadas para la clasificación de riesgos en el Perú; en este mismo capítulo los procesos y metodologías, así como la evidencia casuística presentada son contrastadas en cuadros comparativos.

En el sexto capítulo se analizan y desarrollan las preguntas de investigación, obteniendo conclusiones y brindando detalles de las metodologías y variables empleadas. Para finalizar en el séptimo capítulo se proponen algunas recomendaciones para mejorar los procesos de evaluación de riesgos. 


\section{OBJETIVOS}

\subsection{Objetivo general}

El objetivo general del presente caso de estudio es entender la importancia de las clasificaciones de riesgo, describir y comparar las principales metodologías de evaluación de riesgos para la correcta gestión del riesgo de crédito.

\subsection{Objetivos específicos}

- Determinar las variables claves a considerar en los modelos de riesgo para una correcta evaluación crediticia.

- Contrastar las metodologías y/o modelos de riesgo usados por las empresas calificadoras de riesgos y las empresas financieras. 


\section{PREGUNTAS DE INVESTIGACIÓN}

Como interrogantes sobre el estudio de caso; se tienen las siguientes respecto de los objetivos:

Pregunta general

- ¿Cuál es la importancia de las clasificaciones de riesgo? ¿Qué consideran las principales metodologías de evaluación de riesgos para la correcta gestión del riesgo de crediticio? ¿Cómo se comparan entre ellas?

Preguntas específicas

- ¿Cuáles son las variables claves a considerar en los modelos de riesgo para una correcta evaluación crediticia?

- ¿Cuál es la diferencia entre las metodologías y/o modelos de riesgo usados por las empresas calificadoras de riesgos y las empresas financieras? 


\section{METODOLOGÍA DE RECOLECCIÓN DE LA INFORMACIÓN}

El presente caso de estudio se basa en información secundaria y encuentra como fuente de información teórica y conceptual inicialmente las páginas Web de la biblioteca de la Universidad de Lima y de Google académico, filtrando trabajos de investigación y casos de estudios relacionados al tema de investigación, así como publicaciones especializadas en diarios, y páginas web. Las búsquedas vía web, se realizaron con las palabras clave: riesgo de crédito, modelo rating, clasificación de riesgo, Basilea, asimetría de la información, información privilegiada, etc.

Posteriormente se ingresó a las plataformas Web de la Superintendencia del Mercado de Valores (SMV) y de la Superintendencia de Banca y Seguros y AFP (SBS), de donde se obtuvieron las memorias anuales de los Bancos: Banco de Crédito del Perú, Banco Interbank, Banco BBVA Continental y Banco Scotiabank; de forma complementaria se utilizó la presentación corporativa y los informes de gestión de los bancos antes mencionados, publicados en sus páginas web en la sección de información corporativa y relación con inversionistas.

Por otro lado, a través de las páginas web de las empresas clasificadoras de riesgo: Apoyo \& Asociados Internacionales S.A.C, Pacific Credit Rating - PCR, Equilibrium Clasificadora de Riesgo S.A. y Class \& Asociados S.A., se obtuvieron informes detallados de sus procesos y metodologías para la evaluación de riesgos.

Finalmente con el objetivo de despejar dudas respecto al proceso crediticio en las entidades financieras y de obtener el dato de las clasificaciones otorgadas a un grupo de empresas empleadas como casuística, se realizaron consultas a diversos funcionarios y oficiales relacionados con áreas de administración del riesgo de tres de los más importantes bancos del sistema financiero peruano. 


\section{METODOLOGÍA DE ANÁLISIS DE LA INFORMACIÓN}

El presente trabajo se encuentra basado en un profundo análisis cualitativo. El proceso inicia con la búsqueda de los conceptos clave: "Riesgo de crédito", "Información asimétrica" y "Clasificación de riesgos" como marco conceptual y teórico del caso de estudio.

Posteriormente se recolectó datos provenientes de información pública de las empresas clasificadoras de riesgos y de los 04 principales bancos del sistema financiero peruano; profundizando en su descripción, normativa, regulación y metodologías empleadas para la identificación de riesgos. Una vez identificada y recolectada la información pertinente, de acuerdo al marco de investigación, se sintetizaron y agruparon conceptos y variables generales, para terminar elaborando cuadros descriptivos de los procesos y de cada una de las metodologías conforme a una lógica de análisis cuantitativo y cualitativo relacionada al sector financiero.

Es importante señalar que para el caso de las empresas clasificadoras de riesgo se seleccionaron únicamente las metodologías con alcances para el segmento corporativo, excluyendo metodologías de análisis para otros segmentos, por las distintas consideraciones y enfoques, tales como: metodologías para evaluación de empresas financieras, para empresas de seguros, para fondos de inversión, para proyectos, para emisión de deuda, etc.

Finalmente se elaboró un cuadro comparativo a fin de facilitar su comprensión y análisis; adicionando evidencia empírica que ayudó con la interpretación de resultados.

Las limitaciones del presente trabajo surgen por razones de confidencialidad. La información pública se complementa con manuales de gestión del riesgo de entidades bancarias privadas. De similar manera al mostrar la evidencia empírica se toman de ejemplo resultados de clasificaciones de riesgo de compañías elegidas aleatoriamente. En ambos casos, se reserva la identidad de las empresas analizadas. 


\section{DESCRIPCIÓN DE CASO}

Se sabe que las calificaciones crediticias en general ayudan en la toma de decisiones a los diferentes agentes de la economía (Standard \& Poor's, 2014), pues expresan opiniones de entidades independientes y reconocidas sobre el riesgo de crédito de una empresa determinada.

Si bien con un alto grado de probabilidad las clasificaciones de riesgo son fundadas, pues se sustentan en un análisis profesional y minucioso de información, son también a su vez subjetivas pues no provienen de una implementación estricta o predeterminada de la información, sino también además de la experiencia y criterios metodológicos del analista y de la entidad evaluadora (Class \& Asociados, 2018a).

Ante esta situación surgen las primeras interrogantes ¿Qué información recogen los modelos de clasificación de riesgos? ¿Cuál es el modelo de clasificación de riesgo más acertado? ¿Cuáles son las variables de mayor relevancia? ¿Cuál es la diferencia entre las clasificaciones de las agencias clasificadoras y las de las entidades bancarias?

Es por ello que este trabajo, partiendo de conceptos básicos de riesgo, analiza las diferentes metodologías de clasificación de riesgo existentes en el mercado peruano, compara y sintetiza las mejores prácticas para establecer parámetros relevantes que toda evaluación de riesgos debe considerar. A su vez, detalla recomendaciones como oportunidades de mejora frente al deseo de un correcto y sostenido desarrollo de nuestro mercado financiero.

\subsection{Marco teórico}

\subsubsection{Riesgo de crédito}

Es la posibilidad de que un prestatario o contraparte no pueda cumplir con sus obligaciones y/o compromisos de acuerdo a los términos acordados (Comité de Supervisión Bancaria de Basilea, 1999). 


\subsubsection{Información asimétrica}

La información asimétrica supone que una de las partes en una relación o transacción económica tiene menos información que otra u otras; ello genera dos tipos de problemas sobre los mercados financieros a la vista: la selección adversa (adverse selection) y el riesgo moral (moral hazard), teniendo cada uno el potencial para conducir a los mercados financieros hacia la ineficiencia e inestabilidad (Sánchez-Daza, 2001).

Haciendo referencia al conocimiento incompleto o limitado de la solvencia o capacidad crediticia de los prestatarios, se considera que no existirá un precio o tasa de interés justa a su verdadero valor de mercado (Sánchez-Daza, 2001).

\subsubsection{Clasificación de riesgo}

La Superintendencia de Mercado de Valores (SMV), entidad reguladora de las agencias clasificadoras, la define como la actividad profesional que, sobre la base de la aplicación de una metodología, comprende el estudio, análisis y evaluación para la emisión de una opinión sobre la calidad crediticia de un valor y/o de su emisor (Superintendencia de Mercado de Valores, 2001).

Por otro lado la determinación de una evaluación de riesgo es un juicio basado en análisis cualitativo y cuantitativo de acuerdo al ambiente económico de cada industria o sector (Pacific Credit Rating, 2009); la información es proporcionada por la empresa sujeta a evaluación, así como también es obtenida de fuentes que se consideren fidedignas.

Es importante precisar que a pesar de que algunos métodos cuantitativos son utilizados para determinar ciertos factores de riesgo, la clasificación de riesgo para las empresas clasificadoras es de naturaleza cualitativa. El uso de los análisis cuantitativos permite llegar al mejor juicio cualitativo posible, toda vez que una clasificación de riesgo es una opinión (Pacific Credit Rating, 2009). 


\subsubsection{Agencias clasificadoras de riesgo}

Las agencias clasificadoras de riesgo son entidades que se encargan de clasificar los riesgos relacionados con instrumentos y/o valores financieros de oferta pública (emisiones de deuda) y empresas en general (riesgo de crédito de los emisores).

Las empresas clasificadoras de riesgo existen dentro del mercado financiero y particularmente de manera activa por normativa en el mercado de valores, cumpliendo el rol básico de brindar transparencia al mercado, estrechando la brecha en la asimetría de la información al generar una opinión y un criterio de experto independiente para posteriormente hacerla de conocimiento público; facilitando de esta manera la toma de decisiones para los diferentes agentes del mercado. En el Perú se encuentran exclusivamente autorizadas, reguladas y supervisadas por la Superintendencia de Mercado de Valores (SMV).

Dentro de las más reconocidas a nivel mundial, se encuentran: Moody's, Standard \& Poor's (S\&P) y Fitch Ratings, mientras que en el Perú contamos con un mercado de reducido y concentrado de 04 empresas, tal como se puede verificar en los anexos 1 y 2 .

\subsection{Recolección y transformación de datos de los procesos y metodologías para la clasificación de riesgos}

Como es de saber, existen 02 tipos de instituciones claramente identificadas en el sector financiero como las principales evaluadoras del riego crediticio, estas son las empresas clasificadoras de riesgo y los bancos. Es importante mencionar que cada una de ellas se encuentra enfocada y dirigida de diferentes perspectivas, con distintos objetivos, riesgos, procesos y metodologías, pero trabajando en un mismo mercado.

A pesar de lo anteriormente mencionado, en líneas generales, podemos decir que la principal diferencia en la evaluación que realizan ambos tipos de empresa radica en el sujeto que dispondrá de esta información; mientras que las agencias clasificadoras emiten una opinión o juicio relativo para un tercero y esta información es de carácter público, los bancos emiten un juicio para poder gestionar el riesgo de determinada operación crediticia (riesgo asumido por las entidades bancarias al realizar intermediación financiera) como herramienta de toma de decisiones para ellos mismos; se trata de una información privada y no negociable. 


\subsubsection{Proceso y metodologías en las agencias clasificadoras}

El mercado de agencias clasificadoras en el Perú es bastante reducido y se encuentra concentrado en sólo 04 empresas tal como se verifica en el anexo 2.

En aras de la transparencia, las empresas clasificadoras en sus páginas web, así como también en la página web de Superintendencia de Mercado de Valores, realizan una descripción de lo que constituye su proceso de clasificación de riesgo desde el contacto inicial con el cliente que requiere ser clasificado hasta la emisión y divulgación del informe de clasificación. A continuación un cuadro resumen del proceso que mantienen las agencias clasificadoras en general:

Tabla 6.1

Proceso de clasificación y políticas de difusión de las agencias clasificadoras

\begin{tabular}{|c|c|}
\hline $\begin{array}{c}\text { Clasificación } \\
\text { Inicial }\end{array}$ & $\begin{array}{l}\text { (1) Evaluación preliminar: Se realiza un análisis en función a la documentación e información mínima requerida } \\
\text { recibida (para mayor detalle ver Anexos), además de la información del sector al que pertenece la entidad. } \\
\text { (2) Se realiza una visita a las instalaciones pudiendo realizar entrevistas a sus principales directivos y/o ejecutivos, } \\
\text { obteniendo información privilegiada y de manera directa. } \\
\text { (3) Duración: entre cuatro y ocho semanas y se encuentra a cargo de un equipo de análisis quienes presentan los } \\
\text { resultados iniciales y reciben retroalimentación del Comité de Clasificación } \\
\text { (4) Sesión del Comité de Clasificación: Instancia en donde se decide la clasificación de riesgo a otorgar. }\end{array}$ \\
\hline Divulgación & $\begin{array}{l}\text { De tratarse de una clasificación pública de valores, la agencia clasificadora comunica la clasificación por escrito a la } \\
\text { entidad evaluada así como a la Superintendencia del Mercado de Valores - SMV. } \\
\text { Una vez que se realice la inscripción del instrumento clasificado en el Registro Público del Mercado de Valores } \\
\text { (RPMV) y/o su inscripción o listado en la Bolsa de Valores de Lima (BVL), la agencia clasificadora hace pública la } \\
\text { clasificación otorgada con sus respectivos fundamentos a través de su página web. }\end{array}$ \\
\hline Vigilancia & $\begin{array}{l}\text { Para las agencias clasificadoras las clasificaciones de riesgo involucran una visión de largo plazo pues mantienen una } \\
\text { visión integral, en línea a ello evitan variaciones innecesarias en las clasificaciones. Por el contrario, si se considera que } \\
\text { la desviación es producto de un cambio fundamental en la estructura de la compañía, se realiza la actualización que se } \\
\text { considere prudente. } \\
\text { La clasificación de la emisión se revisa formalmente cada trimestre, o antes si fuera necesario, conforme a los } \\
\text { resultados experimentados. Lo que se pretende con esto es observar si existen desviaciones importantes respecto a las } \\
\text { consideraciones iniciales, y de existir, se establece la comunicación con el emisor para aclarar las causas. Si éstas son } \\
\text { sólo de carácter temporal, la clasificación no se altera y se le ubica bajo mayor observación. }\end{array}$ \\
\hline
\end{tabular}

Fuente: Apoyo \& Asociados, 2018b; Class \& Asociados, 2016b; Equilibrium Clasificadora de Riesgo, 2018b; Pacific Credit Rating (2009)

Elaboración propia

Es importante señalar que tres de las cuatro agencias clasificadoras de riesgo en nuestro país cuentan con el respaldo de reconocidas agencias clasificadoras norteamericanas, aplicando estándares y adaptando diversas metodologías estandarizadas a la realidad 
peruana. En este punto se debe mencionar que los diferentes modelos empleados, analizan diversas variables (factores cuantitativos y cualitativos) y las ponderan en función de su relevancia. De esta manera, los factores de ponderación son dinámicos en el tiempo y pueden variar dependiendo de la industria y el emisor (Apoyo \& Asociados, 2018).

En línea con ello, se debe diferenciar la metodología empleada para evaluar una emisión respecto de la que se aplica a un emisor, la primera referida a los diferentes valores de deuda emitidos o por emitir y la segunda de ellas a la fortaleza o también llamada solvencia financiera de una empresa; es decir, a su capacidad para hacer frente a todos sus compromisos. Por ende existe la posibilidad que una empresa pueda realizar varias emisiones de deuda y que cada una de ellas tenga diferente evaluación pues las clasificaciones se realizan de acuerdo a características individuales (Pacific Credit Rating, 2018).

Para el presente caso de estudio, de acuerdo a los objetivos inicialmente planteados, se estandarizan las metodologías de las diferentes agencias clasificadoras que cuentan con un método específico para clasificación de empresas (no financieras) como herramienta identificadora del riesgo de crédito y de su fortaleza financiera; para ello se elabora un cuadro resumen de las variables empleadas en su proceso metodológico, las cuales se presentan en la Tabla 6.2. 
Tabla 6.2

Metodología de evaluación de riesgos de las empresas clasificadoras peruanas

\begin{tabular}{|c|c|}
\hline \multicolumn{2}{|c|}{ Apreciación de Riesgo sobre la capacidad de pago de la empresa: fortaleza (solvencia) financiera } \\
\hline \multicolumn{2}{|l|}{$\underline{\text { Aspectos Cualitativos }}$} \\
\hline Perfil y riesgo de la Industria & $\begin{array}{l}\text { Analiza los factores que puedan generar variabilidad en la rentabilidad que percibe } \\
\text { cada uno de los participantes o competidores dentro de la industria: } \\
\text {-Barreras de entrada o salida / Posición de mercado y análisis de la competencia / } \\
\text { Análisis de los clientes y proveedores / Características y sensibilidad del sector } \\
\text {-Exposición a cambios sociales, políticos, demográficos, geográficos, regulatorios y } \\
\text { tecnológicos. }\end{array}$ \\
\hline Perfil y riesgo de la Compañía & $\begin{array}{l}\text { - Bienes y servicios brindados: Se verifica la capacidad de producción, la tecnología } \\
\text { de procesos, el suministro de materias primas, etc. } \\
\text {-Finanzas: Se evalúa en qué medida la rentabilidad y respaldo patrimonial y el } \\
\text { performance financiero en general es superior a la de la competencia } \\
\text {-Soporte que pudiera brindarle una matriz o las empresas del mismo Grupo } \\
\text { Económico, así como la integración existente y los compromisos }\end{array}$ \\
\hline Administración y propiedad & $\begin{array}{l}\text { Evaluación de la capacidad y experiencia de los principales gestores del negocio, } \\
\text { manteniendo una adecuada estructura, organizacion y planificación: } \\
\text {-Gobierno Corporativo / Políticas de administración y de inversión / Integridad del } \\
\text { área contable y de auditoría. } \\
\text {-Asimismo, se analizan los antecedentes y referencias de los accionistas, su } \\
\text { experiencia e inluencia en la empresa }\end{array}$ \\
\hline \multicolumn{2}{|l|}{$\underline{\text { Aspectos Cuantitativos }}$} \\
\hline 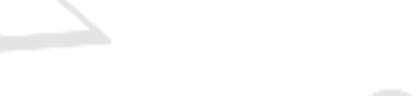 & $\begin{array}{l}\text { Se centra en el perfil financiero de la empresa y en su capacidad para cumplir sus } \\
\text { obligaciones con una combinación de recursos internos y externos. Corresponde a un } \\
\text { juicio respecto a la fortaleza financiera de una determinada empresa }\end{array}$ \\
\hline Situación Financiera & $\begin{array}{l}\text {-Análisis de liquidez, rentabilidad, endeudamiento e indicadores adicionales de } \\
\text { acuerdo a relevancia / Análisis de las contingencias y compromisos } \\
\text {-Fuentes de financiamiento / Acceso al crédito }\end{array}$ \\
\hline Consideraciones financieras adicionales & $\begin{array}{l}\text {-Se considera relevante el análisis de tendencias y proyecciones, debido a que los } \\
\text { estados financieros reflejan sólo información histórica. } \\
\text {-Análisis de sensibilidad y flexibilidad financiera: permite que el emisor cumpla con } \\
\text { sus obligaciones de servicio de deuda y maneje los períodos de volatilidad sin } \\
\text { deteriorar su calidad crediticia. }\end{array}$ \\
\hline \multicolumn{2}{|l|}{$\underline{\text { Otras Consideraciones }}$} \\
\hline Pasivos Contingentes & $\begin{array}{l}\text { Se evalúan las implicaciones que tienen los pasivos contingentes, tales como } \\
\text { compromisos, requerimientos colaterales y pasivos legales, con estos calculan índices } \\
\text { de apalancamiento ajustados }\end{array}$ \\
\hline Seguros y garantías & Se analizará la existencia de mecanismos de resguardo \\
\hline \multicolumn{2}{|l|}{$\underline{\text { Limitaciones de la Metodología }}$} \\
\hline $\begin{array}{l}\text { El proceso de clasificación contable no cons } \\
\text { Las clasificaciones no predicen un porcentaj } \\
\text { Las clasificaciones no representan una opini }\end{array}$ & $\begin{array}{l}\text { e una auditoría de los estados financieros. } \\
\text { robabilidad de incumplimiento para un período de tiempo determinado. } \\
\text { propiado que resulta un emisor como contraparte para un negocio crediticio }\end{array}$ \\
\hline
\end{tabular}

Fuente: Apoyo \& Asociados, 2017; Class \& Asociados, 2016b; Pacific Credit Rating (2017) Elaboración propia

\subsubsection{Proceso y metodologías en los bancos del sistema financiero peruano}

Para el caso de las empresas pertenecientes al sector financiero (bancos), la gestión eficaz de riesgos es fundamental y es considerada punto clave en el enfoque global de la gestión estratégica de los bancos.

Podemos resumir la gestión del riesgo de crédito como el proceso que permite mantener el riesgo de crédito dentro de los parámetros aceptables, establecidos en las 
políticas y procedimientos internos aprobados por el directorio de cada banco, con el objetivo de alcanzar sus objetivos de rentabilidad y eficiencia (Belaunde, 2012).

Dichas políticas y procedimientos les permiten tomar medidas prudentes y oportunas para enfrentar los posibles incumplimientos, con el objeto de minimizar las pérdidas y además definir los criterios y la forma de evaluar, asumir, calificar, controlar y cubrir su riesgo crediticio de manera eficiente y acorde a lo establecido por el órgano regulador (Superintendencia Financiera de Colombia, 2006).

Es tal la importancia de la gestión del riesgo de crédito para los bancos, que estos cuentan con una estructura organizacional que garantiza la solvencia y el desarrollo sostenible de la entidad dentro de un ambiente de control, validación y regulación.

Muy aparte de ello, cuenta con unidades especializadas de análisis (áreas de evaluación de créditos o riesgos) y de soporte de las diferentes etapas del proceso crediticio (áreas de administración de riesgos) en cada segmento de negocio. Este proceso está compuesto de manera estandarizada ( $\sin$ ser exactamente igual para todas las entidades financieras) en tres etapas fundamentales, las cuales se presentan a continuación:

\section{Tabla 6.3}

Proceso crediticio para la evaluación de riesgos de las entidades bancarias en el Perú

\begin{tabular}{|c|c|}
\hline \multirow{2}{*}{ Admisión } & $\begin{array}{l}\text { (1) Inicio en el Área Comercial: Evaluación y análisis de las transacciones individuales correspondientes a la Banca } \\
\text { Comercial, acompañada de un planteamiento tentativo de exposición de riesgo a asumir por el Banco }\end{array}$ \\
$\begin{array}{l}\text { (2) Evaluación del Riesgo Crediticio: Análisis cualitativo y cuantitativo de las empresas y asignación de un rating en } \\
\text { función a la calidad de riesgo crediticio identificado }\end{array}$ \\
$\begin{array}{l}\text { (3) Aprobación de Operaciones: La resolución está a cargo de los diferentes comités de crédito en función a las } \\
\text { facultades delegadas en instancias aprobadoras }\end{array}$ \\
\hline $\begin{array}{c}\text { Seguimiento y } \\
\text { Monitoreo }\end{array}$ & $\begin{array}{l}\text { El proceso de seguimiento involucra la identificación temprana de clientes con potencial de deterioro a través de } \\
\text { diversos sistemas y modelos, enfocandose en la revisión de los que tienen mayor criticidad. }\end{array}$ \\
\hline $\begin{array}{c}\text { Recuperación de } \\
\text { la cartera } \\
\text { problema }\end{array}$ & $\begin{array}{l}\text { Área especializada en la gestión de cobranza de los créditos de la cartera de los clientes deteriorados; la gestión de } \\
\text { cobranza se realiza a través de un conjunto de acciones coordinadas y estructuradas que tienen como finalidad la } \\
\text { adecuada y oportuna recuperación de los créditos y la protección de los intereses e imagen del Banco }\end{array}$ \\
\hline
\end{tabular}

Fuente: Banco de Crédito del Perú, 2004; Banco Interbank (2018)

Elaboración propia

Las metodologías de análisis empleadas por los bancos constituyen una detallada y profunda evaluación de la capacidad crediticia de determinado cliente, basada en 
información cualitativa y cuantitativa; ello de acuerdo a variables históricas de la empresa y del sector en el que se desarrolla.

Con estos parámetros y ponderaciones adicionales para las variables de acuerdo al modelo de riesgos y al apetito de riesgo de cada banco, se asigna una calificación crediticia en base a su capacidad de pago, performance financiero e historial crediticio.

Dicho esto, teniendo en consideración la labor de intermediación financiera que realizan los bancos, el riesgo inherente que presentan sus operaciones y con el fin de agilizar sus procesos de admisión y evaluación, estas entidades utilizan como soporte los sistemas de calificación. Es importante señalar que estos sistemas se encuentran respaldados por herramientas y modelaciones comúnmente llamadas Rating Scoring o Risk Analyst, así como también por herramientas que califican su comportamiento e historial crediticio como el Behavioral Scoring o Buró.

Por otro lado, es importante destacar que los modelos de clasificación de riesgos de los bancos, toman como base parámetros estipulados por Basilea como normativa para el cálculo de las medidas clave de riesgo (para mayor detalle ver anexo 4), las cuales incluyen la probabilidad de incumplimiento (PI), la pérdida en caso de incumplimiento (PCI) y la exposición al producirse el incumplimiento (EPI):

La probabilidad de incumplimiento (PI) es la medida de la probabilidad de que un prestatario al que se ha asignado una calificación según el programa de calificación interna $(\mathrm{CI})$ incurra en un incumplimiento dentro de un horizonte de tiempo de un año.

La pérdida en caso de incumplimiento (PCI) es la medida de la pérdida sobre un préstamo en caso que el prestatario incumpla. Las calificaciones PCI toman en cuenta características tales como la prioridad del derecho, el tipo y la cobertura de la garantía y otros elementos estructurales. La PCI se basa en el concepto de la pérdida económica y se calcula en función del valor actual de los reembolsos, las recuperaciones y los gastos directos e indirectos relacionados (Scotiabank, 2018).

La exposición al producirse el incumplimiento (EPI) mide la exposición prevista en un préstamo al producirse un incumplimiento (Scotiabank, 2018).

Con la información previamente detallada y de similar manera al caso de las empresas clasificadoras, se construyó un cuadro en el que se detallan (sintetizando y 
agrupando) las principales variables consideradas en los modelos de evaluación de riesgos de los bancos en el Perú, obteniendo el siguiente detalle:

Tabla 6.4

Metodología empleada para la evaluación de riesgos de las entidades bancarias

\begin{tabular}{|c|c|}
\hline \multicolumn{2}{|c|}{$\begin{array}{l}\text { Herramienta orientada a evaluar y calificar la calidad crediticia de los clientes, a partir del cálculo de la probabilidad de incumplimiento } \\
\text { de este mismo }\end{array}$} \\
\hline \multicolumn{2}{|l|}{ Aspectos Cualitativos } \\
\hline Análisis de la actividad & Análisis de la empresa, su perfil y experiencia en el negocio \\
\hline Estabilidad del accionariado y gerentes & $\begin{array}{l}\text { Análisis de los principales gestores del negocio, su influencia, respaldo y } \\
\text { compromiso; así como tamién la línea de sucesión ( ) }\end{array}$ \\
\hline Proceso productivo e infraestructura & $\begin{array}{l}\text { Análisis de las condiciones que soportan su capacidad productiva, grado de } \\
\text { vigencia u obsolescencia. }\end{array}$ \\
\hline Análisis del mercado y la industria & $\begin{array}{l}\text { Análisis del sector, concentración, rivalidad, poder de negociación, participación } \\
\text { de mercado, cartera de clientes y proveedores, barreras de entrada y salida, } \\
\text { variación de precios, etc. }\end{array}$ \\
\hline Aspectos sectoriales & $\begin{array}{l}\text { Marco regulatorio y normativo, regulaciones, tasas imposositivas y aranceles, } \\
\text { perspectivas del sector, análisis de oferta y demanda, etc. }\end{array}$ \\
\hline Fuentes de Financiamiento & $\begin{array}{l}\text { Relación con el sistema financiero, capacidad de acceso al crédito: entidades } \\
\text { financieras, proveedores, accionistas, etc. }\end{array}$ \\
\hline \multicolumn{2}{|l|}{ Aspectos Cuantitativos } \\
\hline Tendencias en ventas y márgenes & $\begin{array}{l}\text { A partir de información histórica (estados financieros), análisis horizontal y } \\
\text { vertical del performance financiero de la empresa }\end{array}$ \\
\hline Tendencias en ventas y márgenes & $\begin{array}{l}\text { A partir de información histórica (estados financieros), análisis horizontal y } \\
\text { vertical del performance financiero de la empresa }\end{array}$ \\
\hline Análisis de liquidez, endeudamiento y rentabilidad & $\begin{array}{l}\text { A partir de información histórica (estados financieros), análisis horizontal y } \\
\text { vertical del performance financiero de la empresa, análisis e interpretación de } \\
\text { ratios financieros }\end{array}$ \\
\hline Análisis del respaldo patrimonial & $\begin{array}{l}\text { Análisis de la solvencia patrimonial y estructura de endeudamiento; politicas de } \\
\text { capitalización, reparto de dividendos y de reinversión }\end{array}$ \\
\hline Análisis del flujo de caja / Capacidad de pago & Análisis de la capacidad de generación y cobertura del servicio de deuda \\
\hline \multicolumn{2}{|l|}{ Aspectos de Comportamiento } \\
\hline Historial y experiencia crediticia & $\begin{array}{l}\text { Comportamiento crediticio histórico con el banco evaluador y el sistema } \\
\text { financiero en general (Número de entidades financieras). } \\
\text { (Transaccionabilidad en cuentas, aobregiros, atrasos, renovaciones, morosidad, } \\
\text { protestos, número de operaciones, plazos, etc.) }\end{array}$ \\
\hline \multicolumn{2}{|l|}{ Otras Consideraciones } \\
\hline Estructura de Garantias & Cobertura mediante garantías en respaldo de operaciones crediticias \\
\hline
\end{tabular}

Fuente: Banco de Crédito del Perú, 2004; Banco Interbank (2018); BBVA Continental (2018); Scotiabank (2018) y manuales de gestión de riesgo Elaboración propia

Finalmente, con el fin de facilitar su comprensión y análisis, tomando de base la información obtenida de las diferentes metodologías estudiadas (señalando sus principales variables) y las clasificaciones obtenidas de empresas evaluadas por ambas metodologías, se elaboran los siguientes cuadros comparativos: 


\section{Tabla 6.5}

\section{Cuadro comparativo resumen de las metodologías de evaluación de riesgos}

\begin{tabular}{|c|c|c|}
\hline & $\begin{array}{l}\text { Clasificadoras de } \\
\text { Riesgo en Perú }\end{array}$ & $\begin{array}{c}\text { Sistema } \\
\text { Financiero } \\
\text { Peruano (Bancos) } \\
\end{array}$ \\
\hline \multicolumn{3}{|l|}{ Proceso de Evaluación y Clasificación de Riesgos } \\
\hline \multicolumn{3}{|l|}{ Clasificación } \\
\hline Evaluación preliminar & SI & SI \\
\hline Visita y Consultas & SI & SI \\
\hline Instancia aprobadora: Resolución & SI & SI \\
\hline \multicolumn{3}{|l|}{ Divulgación } \\
\hline Clasificación de carácter público & SI & NO \\
\hline \multicolumn{3}{|l|}{ Vigilancia } \\
\hline $\begin{array}{l}\text { Monitoreo y vigilancia de alertas (Empresa e industria) } \\
\text { Visión de largo plazo hacia el evaluado } \\
\text { Evaluación y Seguimiento trimestral }\end{array}$ & $\begin{array}{l}\text { SI } \\
\text { SI } \\
\text { SI }\end{array}$ & $\begin{array}{c}\text { SI } \\
\text { SI } \\
\text { NO }\end{array}$ \\
\hline \multicolumn{3}{|l|}{ Metodologías de Clasificación de Riesgos } \\
\hline \multicolumn{3}{|l|}{$\underline{\text { Aspectos Cualitativos }}$} \\
\hline $\begin{array}{l}\text { Análisis de la Industria - Macroeconómico } \\
\text { Entorno Operacional } \\
\text { Perfil y estructura de la Compañía } \\
\text { Calidad de la Gerencia } \\
\text { Análisis y respaldo del Grupo Económico }\end{array}$ & $\begin{array}{l}\text { SI } \\
\text { SI } \\
\text { SI } \\
\text { SI } \\
\text { SI }\end{array}$ & $\begin{array}{l}\text { SI } \\
\text { SI } \\
\text { SI } \\
\text { SI } \\
\text { SI }\end{array}$ \\
\hline \multicolumn{3}{|l|}{ Aspectos Cuantitativos } \\
\hline $\begin{array}{l}\text { Ajuste Experto de los Estados Financieros } \\
\text { Anáslisis de la Situación Financiera } \\
\text { Fuentes Acceso al Crédito (fuentes de financiamiento) } \\
\text { Flujos de caja y efectivo / Cobertura del servicio de deuda } \\
\text { Análisis de Sensibilidad } \\
\text { Perspectivas, tendencias y Proyecciones de Flujos }\end{array}$ & $\begin{array}{l}\text { NO } \\
\text { SI } \\
\text { SI } \\
\text { SI } \\
\text { SI } \\
\text { SI }\end{array}$ & $\begin{array}{c}\text { SI } \\
\text { SI } \\
\text { SI } \\
\text { SI } \\
\text { SI } \\
\text { NO }\end{array}$ \\
\hline \multicolumn{3}{|l|}{ Aspectos Comportamentales } \\
\hline $\begin{array}{l}\text { Transaccionabilidad en cuentas } \\
\text { Efectivividad, Atrasos, Renovaciones, Refinanciamientos } \\
\text { Historial Crediticio con el Banco evaluador y el Sistema }\end{array}$ & $\begin{array}{l}\text { NO } \\
\text { NO } \\
\text { NO }\end{array}$ & $\begin{array}{l}\text { SI } \\
\text { SI } \\
\text { SI }\end{array}$ \\
\hline \multicolumn{3}{|l|}{$\underline{\text { Otras Consideraciones }}$} \\
\hline Contingencias, compromisos y estructura de garantías & SI & SI \\
\hline \multicolumn{3}{|l|}{ Sobre la Metodología } \\
\hline Elaborada en base a la experiencia del evaluador & SI & SI \\
\hline Elaborada en base al amplio portaforlio de clientes (Segmenta de acuerdo al tamaño) & NO & SI \\
\hline Elaborada en base a un apetito de riesgo & NO & SI \\
\hline Adopción de metodologías conservadoras (frente a riesgos evaluados por Basilea) & NO & SI \\
\hline Opinión sobre la capacidad crediticia (cumplimiento de obligaciones asumidas) & SI & SI \\
\hline Juicios emitidos independientes (marginando el conflicto de intereses) & SI & SI \\
\hline Predicción de probabilidad de default o incumplimiento & NO & SI \\
\hline
\end{tabular}

Fuentes: Apoyo \& Asociados (2017); Banco de Crédito del Perú (2004); Banco Interbank (2018); BBVA Continental (2018); Class \& Asociados (2016); Pacific Credit Rating (2017);

Scotiabank (2018)

Elaboración propia 
Tabla 6.6

Casuística comparativa de las metodologías analizadas

\begin{tabular}{|c|c|c|}
\hline & $\begin{array}{l}\text { Rating } \\
\text { Clasificadoras de } \\
\text { Riesgo }\end{array}$ & $\begin{array}{c}\text { Rating } \\
\text { Bancos }\end{array}$ \\
\hline \multicolumn{3}{|l|}{ Empresa 1 (Empresa Comercializadora) } \\
\hline $\begin{array}{l}\text { Importante experiencia de la compañía en el giro de negocio, lo que le ha permitido posicionarse en el } \\
\text { mercado. La calificación se encuentra limitada por el alto apalancamiento explicado parcialmente por } \\
\text { los significativos anticipos de clientes, y la menor generación operativa del periodo }\end{array}$ & A- & \\
\hline $\begin{array}{l}\text { Si bien se verifica una importante experiencia en el sector, la empresa mantiene una importante } \\
\text { concentración de sus ventas en clientes estatales, viendo afectada su actividad y márgenes ante las } \\
\text { menores compras realizadas por empresas del estado ante el ruido político. } \\
\text { Presenta un incremento en sus niveles de endeudamiento producto de los mayores financiamientos de } \\
\text { inventarios. }\end{array}$ & & $\mathrm{BBB}+$ \\
\hline \multicolumn{3}{|l|}{ Empresa 2 (Servicios Públicos) } \\
\hline \multicolumn{3}{|l|}{$\begin{array}{l}\text { Cuenta con el respaldo del estado Peruano como único accionista, mantiene una facturación estable en } \\
\text { los último años, contando con una importante capacidad de generación, viene realizando importantes } \\
\text { inversiones con el objetivo de mejorar su capacidad }\end{array}$} \\
\hline $\begin{array}{l}\text { Empresa con un adecuado performance financiero, manteniendo adecuados niveles de actividad y una } \\
\text { importante generación de caja sin comprometer; presenta superavitarios niveles de liquidez e ínfimos } \\
\text { niveles de apalancamiento. } \\
\text { Si bien no cuenta con garantías en respaldo de sus líneas de crédito, se verifica el respaldo del } \\
\text { FONAFE, al pertenecer al grupo de empresas del Estado. }\end{array}$ & & AAA \\
\hline \multicolumn{3}{|l|}{ Empresa 3 (Empresa productora y comercializadora) } \\
\hline $\begin{array}{l}\text { Sus ingresos mantienen un adecuado desempeño, además se considera la recomposición de sus líneas } \\
\text { de negocio en productos con mayor margen, así como la mejora de sus indicadores de liquidez, } \\
\text { asociado al reperfilamiento de la deuda financiera. }\end{array}$ & $\mathrm{BBB}+$ & \\
\hline $\begin{array}{l}\text { La empresa presenta una mejora en su performance financiero, sin embargo aún mantiene una } \\
\text { concentración del } 20 \% \text { de su cartera de clientes con empresas del estado, si bien muestra un } \\
\text { incremento en sus niveles de endeudamiento, se debe destacar que sus niveles de liquidez mejoran } \\
\text { luego del reperfilamiento realizado de la deuda de corto plazo que financió las inversiones realizadas } \\
\text { en activos fijos (planta de producción) }\end{array}$ & & \\
\hline \multicolumn{3}{|l|}{ Empresa 4 (Empresa constructora) } \\
\hline $\begin{array}{l}\text { Mantiene una adecuada trayectoria en el mercado peruano, con crecimiento en su actividad y un } \\
\text { importante backlog, mantiene bajos niveles de endeudamiento y pertenece a un grupo economico de } \\
\text { importante prestigio }\end{array}$ & A & \\
\hline $\begin{array}{l}\text { En lineas generales mantiene un adecuado performance financiero (crecimiento en su actividad, } \\
\text { superavitarios niveles de liquidez y bajos niveles de apalancamiento) y con un importante backlog de } \\
\text { obras adjudicadas; sin embargo se desarrolla en un sector altamente competitivo por lo que su } \\
\text { actividad y márgenes se encuentran sujetos a los contratos que llegue a adjudicarse }\end{array}$ & & $\mathrm{BBB}+$ \\
\hline
\end{tabular}

Fuentes: Apoyo \& Asociados (2017); Banco de Crédito del Perú (2004); Banco Interbank (2018); BBVA Continental (2018); Class \& Asociados (2016); Pacific Credit Rating (2017);

Scotiabank (2018)

Elaboración propia 


\section{ANÁLISIS Y DISCUSIÓN DE RESULTADOS}

\subsection{Conclusión principal}

Se concluye y se obtiene como premisa que la información en general es clave para el funcionamiento de los mercados (mercados financieros, de valores y de capitales), al ser la herramienta esencial para la toma de decisiones de los diferentes agentes económicos (inversionistas, prestamistas, etc.), encontrando de esta manera la importancia de los diferentes metodologías de clasificación de riesgos, puesto que correctamente elaboradas y posteriormente interpretadas constituyen una herramienta que facilita la toma de decisiones.

\subsection{Conclusiones secundarias}

\subsubsection{Variables claves de las metodologías analizadas}

Luego de la consolidación de las distintas metodologías realizada, se identifican tres grupos de variables clave a considerar:

Grupo 1: Variables cualitativas, tales como el análisis del sector, el perfil de la empresa, el análisis del mercado y el entorno, el gobierno corporativo, el grupo económico, etc.

Grupo 2: Variables cuantitativas, indicadores financieros que evalúan la situación actual de la empresa así como la evolución de su performance financiero, la capacidad para afrontar sus obligaciones y sus mecanismos de cobertura.

Grupo 3: Análisis del comportamiento, en base a su correcta experiencia e historial crediticio con terceros y el cumplimiento de sus obligaciones.

\subsubsection{Principales diferencias en las metodologías analizadas}

De acuerdo a las tablas expuestas para cada una de las metodologías, se identifican las principales diferencias: 


\section{- El adecuado uso de los Estados Financieros}

Para las empresas clasificadoras, la clasificación de riesgos es de naturaleza cualitativa, siendo la información cuantitativa un soporte de su opinión; mientras que los bancos le otorgan una mayor consideración a las variables cuantitativas.

Si bien la metodología empleada por las empresas clasificadoras requiere de estados financieros auditados, en ningún caso estos son auditados por las empresas clasificadoras. A diferencia de los bancos, su metodología carece de un ajuste en base a criterios de evaluación de acuerdo a la experiencia del evaluador o analista "ajuste experto".

Las empresas clasificadoras consideran en su evaluación cuantitativa las tendencias y proyecciones de flujo de caja, mientras que los bancos no, ello de acuerdo al importante sesgo que pueden generar los distintos escenarios planteados: conservadores o flexibles.

En este punto se debe precisar que a diferencia de las opiniones objetivas que puedan brindar las empresas clasificadoras para un tercero, la clasificación de riesgos para un banco es para este mismo y específicamente para asumir un riesgo propio.

\section{- El análisis del comportamiento crediticio (historial crediticio)}

Los bancos consideran este análisis a diferencia de las empresas clasificadoras. Su importancia radica toda vez en que el análisis cuantitativo a veces no considera variables de comportamiento en el tiempo, pudiendo recoger señales de alerta temprana (atrasos, renovaciones, movimientos en cuenta, etc.) antes de su materialización en los estados financieros.

\section{- Alineación con un apetito de riesgo}

Las clasificaciones asignadas por los bancos en contraste a las clasificaciones de las empresas clasificadoras se alinean al apetito de riesgo de la entidad bancaria, ello conforme a su estrategia, calidad crediticia evaluada y al posible nicho de 
negocio. En el caso de las clasificadoras, esto no sucede porque estas no brindan servicios financieros.

\section{- Determinación de una probabilidad de incumplimiento}

Las clasificaciones de riesgo realizadas por los bancos a diferencia de las empresas clasificadoras indican una probabilidad de incumplimiento o de default, la cual se ajusta y toma precisión con la mayor experiencia en la evaluación de empresas.

En otras palabras mientras mayor sea la base de empresas evaluadas, se obtendrán resultados más precisos. Ante ello verificamos que la experiencia de las empresas clasificadoras en el Perú, a pesar de contar con el respaldo de las empresas clasificadoras internacionales, es de tan sólo 25 años; mientras que en el sector financiero tomando de ejemplo al Banco de Crédito del Perú - BCP, el banco con mayor presencia en el mercado peruano, su experiencia es de más de 120 años.

También podemos deducir que las metodologías empleadas por los bancos cumplen con medidas de riesgo adicionales (medidas impuestas en los acuerdos de Basilea).

\subsubsection{Principales diferencias en los procesos metodológicos}

Se identifican básicamente dos diferencias en los procesos metodológicos empleados para la clasificación de riesgos:

\section{- El carácter de la clasificación}

Mientras que las empresas clasificadoras de riesgo son reconocidas como fuente de información del mercado (carácter público), las entidades bancarias no alimentan al mercado con una clasificación, esta es de uso privado para su propia adopción de riesgo. 


\section{- Periodicidad de las evaluaciones}

Si bien ambos procesos consideran un seguimiento y monitoreo continuo, las empresas clasificadoras evalúan de manera integral a las instituciones de manera trimestral, mientras que los bancos lo realizan de manera anual.

\subsubsection{Resultados de la casuística expuesta}

Con el cuadro comparativo de la casuística tomada de ejemplo (de empresas de diversos sectores, elegidas al azar), podemos observar que en todos los casos las clasificaciones otorgadas por las empresas clasificadoras son menos ácidas que las clasificaciones emitidas por las entidades bancarias.

Adicionalmente se verifica que las empresas clasificadoras otorgan un importante peso a las variables cualitativas, resaltando: la relación comercial con empresas del Estado y el respaldo del grupo económico.

Por otro lado las entidades bancarias le otorgan un importante peso a sus variables y resultados cuantitativos, como es el caso de la empresa con deuda recientemente reperfilada por una mala estructura de financiamiento. 


\section{RECOMENDACIONES}

A continuación, se detallan las recomendaciones:

De acuerdo a los informes de clasificación de riesgos y a la experiencia de las empresas clasificadoras, así como de las entidades bancarias:

- Los diferentes agentes económicos y particularmente las empresas, pueden encontrar en los informes de clasificación de riegos un importante valor agregado como fuente de información para la gestión de su riesgo y toma de decisiones.

- Las empresas que aún no acceden al crédito bancario y aquellas que proyectan requerir mayor fondeo futuro, podrían guiarse de análisis como el presente para enfocarse en trabajar aspectos de sus cuentas financieras, comportamiento e historial crediticio, con la finalidad de prepararse y lograr mayores niveles de financiación o acceso al crédito en el futuro.

- Tanto las agencias clasificadoras como las entidades bancarias podrían fomentar realizar benchmarks; así como también adoptar adicionalmente mecanismos que sumen a sus metodologías propias:

Tangiblemente los benchmarks se podrían enfocar de diferentes perspectivas como por ejemplo: (i) el amplio desarrollo analítico que mantienen las agencias clasificadoras a nivel cualitativo y macro del entorno; y (ii) en la información privilegiada que mantienen las entidades bancarias respecto al comportamiento crediticio de las empresas sujeto de análisis.

Por otro lado las empresas clasificadoras podrían adoptar las buenas prácticas del análisis crítico que mantienen los bancos hacia los estados financieros, que inclusive consideran ajustes de experto, mientras que los bancos podrían evaluar implementar el análisis de proyecciones y de tendencias en escenarios conservadores con el objetivo de sincerar y aproximar más el grado de certeza respecto a la emisión de una opinión. 
- A pesar de ello, es innegable señalar que las oportunidades de mejora son varias, y muchas de ellas aún no son recogidas o adoptadas por algún modelo. Por ejemplo, el considerar un análisis de comportamiento que muestre tendencias y no sólo un corte estacional de determinado momento de tiempo. La foto no siempre es la misma en diferentes periodos del año.

- Por otro lado, ahora se entiende con mayor claridad el papel de las empresas clasificadoras, se podría tratar de incentivar su participación y labor activa y no limitarla sólo al mercado de valores, pues esta es la única manera que aumente su experiencia en el mercado peruano. 


\section{REFERENCIAS}

Apoyo y Asociados (2017). Metodología Maestra de Clasificación de Empresas No

Financieras. Recuperado de http://www.aai.com.pe/wp-

content/uploads/2017/01/Metodología-Maestra-Empresas-No-Financieras.pdf

Apoyo y Asociados (2018a). Memoria Anual 2017. Recuperado de

http://www.smv.gob.pe/ConsultasP8/temp/Memoria Anual 2017.pdf

Apoyo y Asociados (17 de Noviembre de 2018). Proceso de clasificación. Recuperado de http://www.aai.com.pe/proceso-de-clasificacion/

Banco de Crédito del Perú (2004). Evolución del BCP, Unidades de Negocios, Administración de Riesgos, Unidades de Apoyo. Recuperado de https://ww3.viabcp.com/connect/NuestroBanco/pdf2003/1EvoluciondelBCP.pdf

Banco Interbank (2018). Memoria Anual 2017. Recuperado de https://interbank.pe/documents/20182/2263274/memoria-anual2017.pdf/bf59dc45-ed54-426e-a469-b72aa02a3fc5

BBVA Continental (2018). Memoria Anual 2017. Lima. Recuperado de https://extranetperu.grupobbva.pe/memoria2017/descargas/BBVA-ContinentalMA-2017.pdf

Belaunde, G. (17 de Noviembre de 2018). Gestionar el riesgo de crédito: ¿qué es y quiénes deberían hacerlo? | Blogs Gestión. Recuperado de https://gestion.pe/blog/riesgosfinancieros/2012/01/gestionar-el-riesgo-decredito.html?ref=gesr

Class y Asociados (2016a). Categorías y simbologías. Recuperado de http://www.classrating.com/simbologia.pdf

Class y Asociados (2016b). Metodología de empresas. Recuperado de http://www.classrating.com/wp-content/uploads/2016/11/Metodo-Empresas.pdf

Class y Asociados (18 de Noviembre de 2018) ¿Qué es la clasificación de riesgo? Recuperado de http://www.classrating.com/que-es-la-clasificacion-de-riesgo/

Class y Asociados (2018b). Memoria Anual 2017. Recuperado de http://www.smv.gob.pe/ConsultasP8/temp/MemoriaClass2017.pdf

Comité de Supervisión Bancaria de Basilea (1999). Principios para la Administración del Riesgo de Crédito Documento consultivo emitido por la Comisión de Basilea de Supervisión de Bancos. Basilea. Recuperado de http://www.asbasupervision.com/es/todos/biblioteca-virtual-asba/gestion-deriesgos/riesgo-de-credito/144-gr-rc03/file

Comité de Supervisión Bancaria de Basilea (2014). Basilea III: Coeficiente de 
Financiación Estable Neta. Recuperado de www.bis.org

El Peruano (19 de Noviembre de 2018). Reglamento de Empresas Clasificadoras de Riesgo. Recuperado de https://busquedas.elperuano.pe/normaslegales/reglamentode-empresas-clasificadoras-de-riesgo-resolucion-no-032-2015-smv01-1324463-1/

Equilibrium Clasificadora de Riesgo (2018a). Memoria Anual 2017. Recuperado de http://www.smv.gob.pe/ConsultasP8/temp/Memoria 2017 R00004.pdf

Equilibrium Clasificadora de Riesgo (2018b). Políticas de difusión de las clasificaciones. Recuperado de https://www.equilibrium.com.pe/Politicadifusion.pdf

Fitch Ratings (19 de Noviembre de 2018). Escala de Calificaciones. Recuperado de https://www.fitchratings.com/site/home

García, J., y Salazar, P. (2005). Métodos de Administración y Evaluación de Riesgos. Universidad de Chile. Recuperado de http://repositorio.uchile.cl/tesis/uchile/2005/garcia_j2/sources/garcia_j2.pdf

Jimenez, R. (2008). El comité de Basilea y sus principios básicos. El comité de Basilea y sus principios básicos. Recuperado de http://blog.pucp.edu.pe/blog/renzojimenez/2008/06/10/el-comite-de-basilea-y-susprincipios-basicos/

Lopez, I. (19 de Noviembre de 2018). Basilea, Acuerdos. Recuperado de http://diccionarioempresarial.wolterskluwer.es/Content/Documento.aspx?params= H4sIAAAAAAAEAMtMSbF1jTAAASMjY1MztbLUouLM_DxbIwMDS0NDA1 OQQGZapUt-ckhlQaptWmJOcSoAMIbOTDUAAAA=WKE

Muñoz, D. (2014). Estructura de tasa óptima para líneas de crédito de acuerdo con el perfil de riesgo. Colegio de estudios superiores de administración - CESA. Recuperado de https://repository.cesa.edu.co/bitstream/handle/10726/1415/TMF00322.pdf?sequen ce $=1 \&$ is Allowed $=\mathrm{y}$

Pacific Credit Rating (2009). Manual de Clasificación de Riesgo Perú. Recuperado de www.ratingspcr.com

Pacific Credit Rating (2017). Metodología de calificación de riesgo de instrumentos de deuda de corto, mediano y largo plazo, acciones preferentes y emisores. Recuperado de www.ratingspcr.com

Pacific Credit Rating (2018). Memoria Anual 2017. Recuperado de http://www.smv.gob.pe/ConsultasP8/temp/Memoria 2017 PCR.pdf

Parodi, C. (17 de Noviembre de 2018). La crisis financiera de los Estados Unidos | Blogs Gestión. Recuperado de https://gestion.pe/blog/economiaparatodos/2012/05/lacrisis-financiera-de-los-es-3.html?ref=gesr

S\&P Global. (2018). Definiciones de calificaciones de riesgo. Recuperado de http://www.standardandpoors.com. 
Sánchez-Daza, A. (2001). Información asimétrica y mercados financieros emergentes: el análisis de Mishkin. México. Recuperado de http://www.redalyc.org/pdf/413/41303402.pdf

Sariego, E. (2012). Basilea y Riesgo Soberano: Un peligroso esquema de incentivos. Universidad de Chile. Recuperado de http://repositorio.uchile.cl/bitstream/handle/2250/144696/Tesis - Basilea y Riesgo Soberano- Un peligroso esquema de incentivos.pdf?sequence $=1 \&$ isAllowed $=\mathrm{y}$

Scotiabank (2018). Construyendo la economía de todos: Memoria Anual 2017. Recuperado de https://www.scotiabank.com/content/dam/scotiabank/canada/en/documents/about/ BNS2017_AR_Spanish.pdf

Standard \& Poor's (2014). Guía sobre aspectos fundamentales de las calificaciones crediticias ¿Qué son las calificaciones crediticias y cómo funcionan? Recuperado de www.UnderstandingRatings.com

Superintencia de entidades financieras y cambiarias (2003). Basilea II: Hacia un nuevo esquema de medición de riesgos. Recuperado de https://www.felaban.net/archivos_boletines_clain/archivo20140722153358PM.pdf

Superintendencia de Mercado de Valores (2001). SMV Superintendencia del Mercado de Valores. Lima. Recuperado de http://www.smv.gob.pe/sil/RSMV00001500032001.pdf

Superintendencia de Mercado de Valores (19 de Noviembre de 2018). SMV Superintendencia del Mercado de Valores: Informe de Clasificación. Recuperado de http://www.smv.gob.pe/Frm_InformeClasificacion?data=E08DBE3022E394AE03 746A7A321CBDDFE3C434D8CA

Superintendencia Financiera de Colombia (2006). Reglas relativas a la gestión del riesgo crediticio. Recuperado de http://www.fasecolda.com/files/7413/8438/0663/ce_100_de_1995_cap_ii.pdf 


\section{BIBLIOGRAFÍA}

Calderón Elías, M. (2004). La gestión bancaria en los riesgos de crédito: Una aplicación al caso peruano para empresas y corporaciones. Lima: Universidad de Lima.

Chu Rubio, J. M. (2009). Fundamentos de finanzas: Un enfoque peruano (7. ${ }^{\mathrm{a}}$ ed.). Lima: Advisory Asesoría Financiera.

Gómez Fernández-Aguado, P., y Partal Ureña, A. (2010). Gestión y control del riesgo de crédito en la banca. Madrid: Delta.

Marthans León, J. J. (2001). Flujos de capital y dinámica de créditos: El caso peruano. Lima: Universidad de Lima.

Mishkin, F. S. (2008). Moneda, banca y mercados financieros (8. ${ }^{a}$ ed.). Naucalpán de Juárez: Pearson Educación.

Pozo García, Eva María del, y Gil Fana, J. A. (2006). Modelos de control de la solvencia en seguros no-vida. Madrid: Universidad Complutense de Madrid.

Raposo Santos, J. M., y Mascareñas Pérez - Iñigo, J. (2009). El nuevo acuerdo de capital de Basilea: Estimación de un modelo de calificación de pequeñas y medianas empresas para evaluar el riesgo de crédito. Madrid: Universidad Complutense de Madrid. 


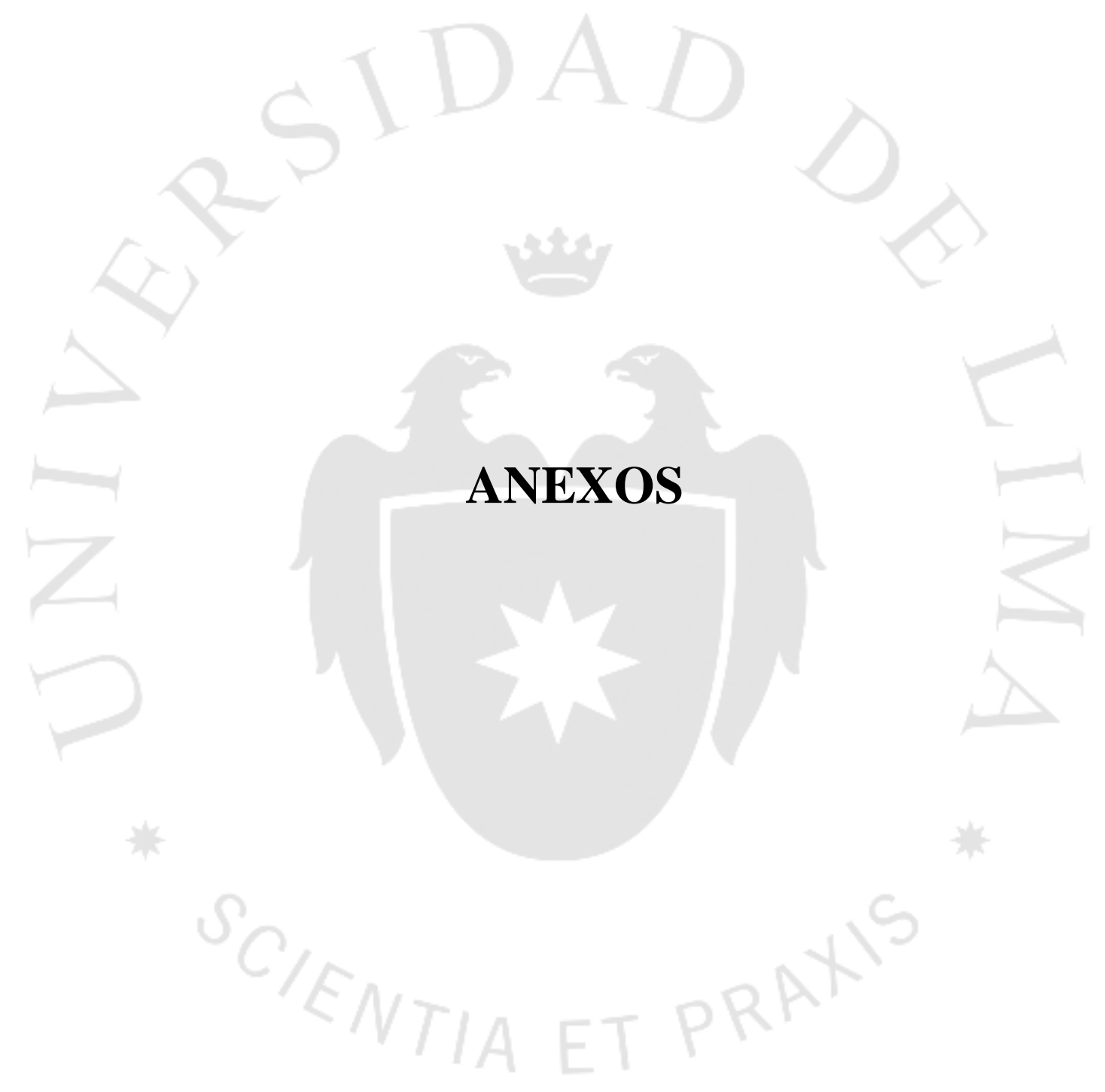




\section{Anexo 1: Empresas clasificadoras de riesgo en el Perú}

\section{Apoyo \& Asociados Internacionales S.A.C.}

Conocida comercialmente como Clasificadora de Riesgo Apoyo \& Asociados fue fundada en 1993 por el Grupo Apoyo (Perú) en asociación con la empresa Clasificadores Asociados y Cía. Ltda., una de las empresas líderes del sistema de clasificación de riesgo en Chile, con la finalidad de prestar servicios de categorización o clasificación de riesgo de valores inmobiliarios e instrumentos financieros en general y de personas jurídicas.

En 1995, IBCA Limited, la principal empresa inglesa en la industria de clasificación de riesgo, quien posteriormente fue adquirida en 1997 por Fitch Rating adquiere el 20\% de participación de Apoyo \& Asociados. En 1998, luego de que fuera aprobado el nuevo Reglamento de Empresas Clasificadoras de Riesgo por la CONASEV (actualmente SMV), el Grupo Apoyo vendió su participación a Holding Rating Perú S.A.C.(Apoyo \& Asociados, 2018a)

En la actualidad, con 25 años de experiencia en el sector, sumado a la experiencia de su socio Fitch Ratings a nivel internacional, se mantiene como la empresa clasificadora de riesgo de mayor presencia en el mercado peruano.

En ese sentido, Apoyo \& Asociados ha clasificado a la mayoría de las principales emisiones realizadas en el país, teniendo una participación significativa en la clasificación de financiamientos estructurados, así como en las clasificaciones de empresas corporativas e instituciones financieras.

\section{Pacific Credit Rating S.A.C. (PCR)}

Es una empresa clasificadora de riesgos de capitales peruanos. Inició operaciones en 1993 bajo el nombre Jasaui \& Asociados, empresa consultora pionera en la clasificación de riesgo de títulos valores en el Perú (Pacific Credit Rating, 2018).

En 1995, mediante un joint-venture agreement con Duff \& Phelps Credit Rating Co. (EEUU) forman Duff \& Phelps del Perú - DCR Perú. Posteriormente, en el año 2000 se da origen a Clasificadora de Riesgo Pacific Credit Rating S.A.C. (PCR). Actualmente, PCR cuenta con 25 años de experiencia en el sector y es la clasificadora latinoamericana 
más grande, manteniendo presencia en 11 países de manera directa y contando con oficinas locales. En línea con ello se ha convertido en la única clasificadora de riesgo en América Latina que ha adecuado sus códigos y procedimientos a las recomendaciones de IOSCO para las agencias clasificadoras de riesgo (Pacific Credit Rating, 2018).

\section{Equilibrium Clasificadora de Riesgo S.A.}

Es una agencia clasificadora de riesgos fundada en 1996 en el Perú en asociación con Thomson Financial Bankwatch, la clasificadora de riesgo más grande a escala global para entidades financieras. En el año 2000, su accionariado total así como los derechos sobre su marca a escala internacional fueron adquiridos por Moody's Corporation, convirtiéndose de esta manera en su subsidiaria directa.(Equilibrium Clasificadora de Riesgo, 2018a).

La firma, en la actualidad, tiene presencia en países de Centroamérica como Panamá, Honduras y El Salvador, encontrando en los fondos de inversión y las instituciones financieras (bancos, financieras, cajas y seguros) la base de sus clientes (Equilibrium Clasificadora de Riesgo, 2018a).

\section{Class \& Asociados S.A.:}

Es una empresa peruana constituida en 1995 bajo el nombre de Feller Rate Pedal SA clasificadora de riesgo, con la finalidad de dedicarse a la clasificación de riesgo de valores representativos de deuda de oferta pública, pudiendo realizar actividades complementarias (El Peruano, 2015).

En la actualidad es la única empresa clasificadora que no cuenta con un socio internacional estratégico. 


\section{Anexo 2: Participación de mercado de las empresas clasificadoras en el Perú}

Participación de mercado según empresa clasificadora por número de clientes - 2017

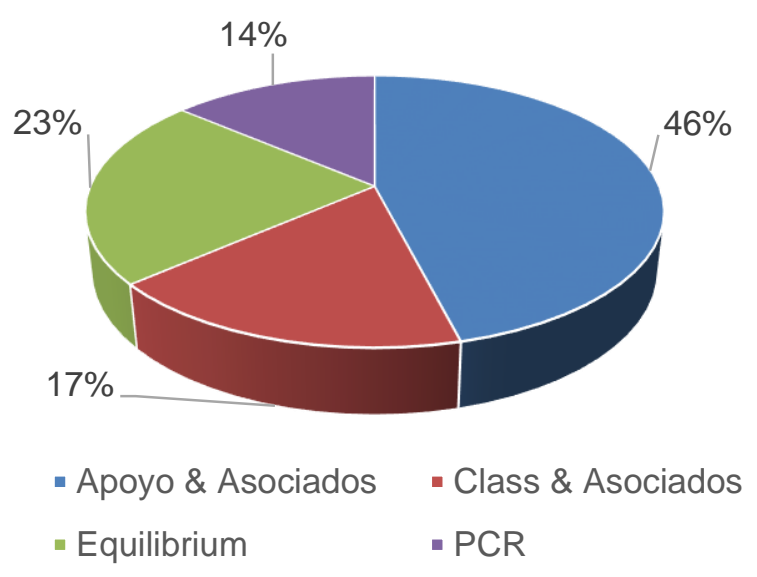

Nota: El gráfico discrimina el número total de clientes atendidos por agencias clasificadoras del número de atenciones por cliente.

Fuente: (Superintendencia de Mercado de Valores, 2018)

Elaboración propia

Participación de mercado según empresa clasificadora por facturación (2016-217)

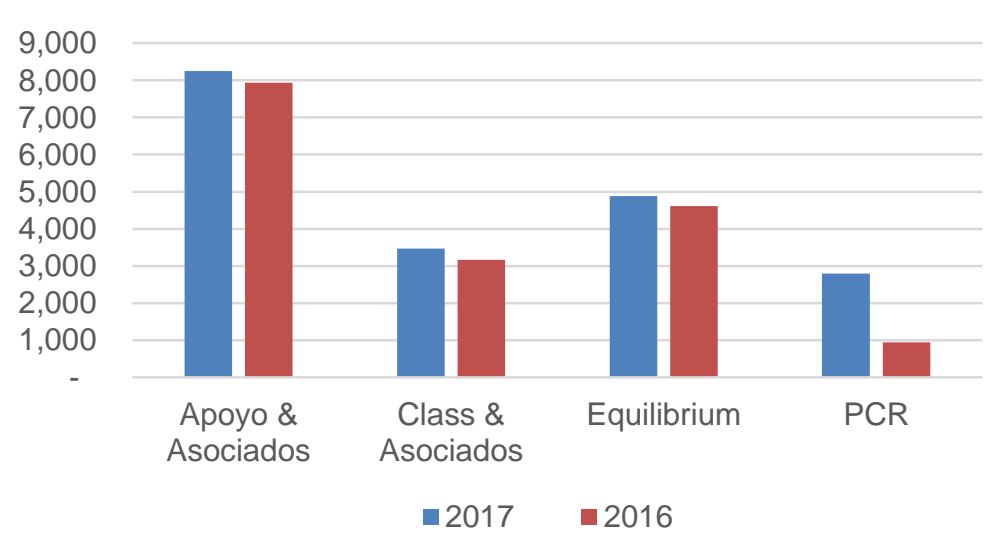

Nota: El gráfico considera los ingresos totales de manera anual por institución. Fuente: (Apoyo \& Asociados, 2018a; Class \& Asociados, 2018b; Equilibrium Clasificadora de Riesgo, 2018a; Pacific Credit Rating, 2018)

Elaboración propia 


\section{Anexo 3: Simbología de las empresas clasificadoras de riesgo}

Generalmente, las calificaciones se expresan como grados en letras que van, por ejemplo, desde 'AAA' a la 'D' a fin de comunicar la opinión de la agencia sobre el nivel relativo de riesgo crediticio. Por otro lado se debe considerar:

- Cada agencia o empresa clasificadora utiliza una escala de clasificación específica para publicar sus opiniones.

- Las opiniones o clasificaciones de empresas clasificadoras en el Perú son independientes a las de empresas clasificadoras internacionales. Si bien las simbologías, escalas e interpretaciones son similares, son distintos los niveles de equivalencias. Es un sesgo comparar una empresa o activo con el mejor rating a nivel nacional con una empresa o activo con el mejor rating a nivel internacional.

Simbología de las empresas clasificadoras de riesgo

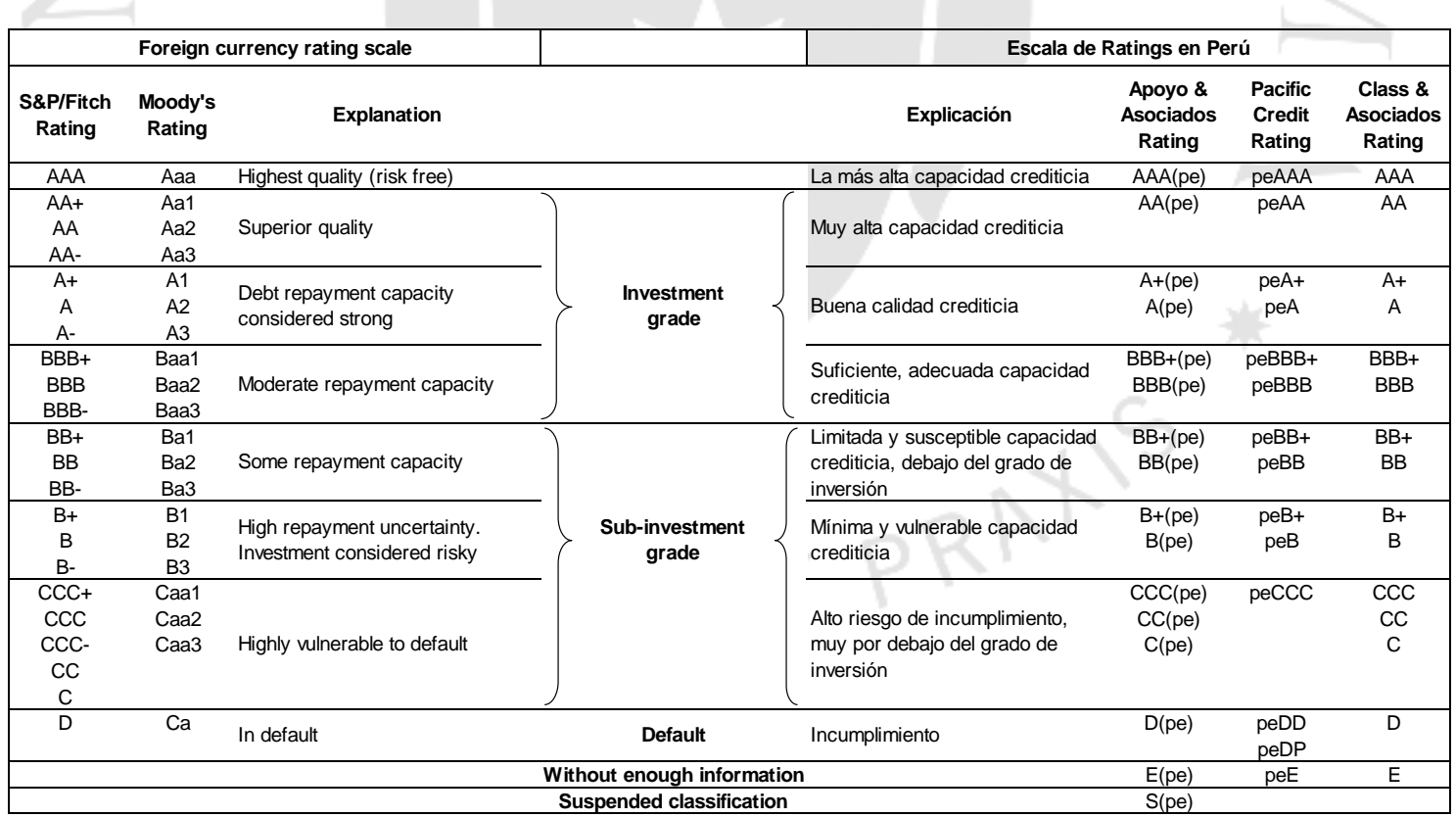

Nota: Adaptado de las simbologías de las empresas clasificadoras de riesgo en el Perú Fuente: (Apoyo \& Asociados, 2018b; Class \& Asociados, 2016a; Fitch Ratings, 2018; Pacific Credit Rating, 2017; S\&P Global, 2018)

Elaboración propia 


\section{Anexo 4: Comité de Supervisión Bancaria de Basilea (CSBB)}

Fue establecido en 1975 por los presidentes de los bancos centrales de los once países miembros del Grupo de los Diez (G-10) de aquel momento y tuvo su origen a raíz de la crisis financiera internacional originada por el cierre del Bankhaus Hersttat en Alemania en 1974, con la finalidad de restaurar la confianza y estabilidad del sistema financiero. En la actualidad la CSBB es una organización mundial que reúne a las más importantes autoridades de supervisión bancaria, con la finalidad de establecer parámetros para permitan fortalecer la solidez de los sistemas financieros (Jimenez, 2008).

\section{BASILEA I}

Es el primer acuerdo publicado en 1988 por el CSBB, este propuso un conjunto de recomendaciones para establecer un capital mínimo que debía tener una entidad bancaria en función de los riesgos que afrontaba (riesgo de crédito, riesgo de mercado y riesgo tipo de cambio) (Sariego, 2012).

Basilea I tuvo un rol muy importante en el fortalecimiento de los sistemas bancarios a nivel mundial, homogeneizando los requerimientos de solvencia de las instituciones financieras. Entró en vigor en más de 130 países.

\section{BASILEA II:}

Acuerdo publicado en el 2004 dada la limitación de Basilea I en la sensibilización del riesgo de crédito para los distintos prestatarios (consideraba que los créditos tenían la misma probabilidad de incumplir); si bien se mantiene la misma definición de Basilea I con relación al riesgo de crédito, se establecen metodologías adicionales para el cálculo de los requerimientos de capital por riesgo de crédito.

Para el riesgo de crédito los bancos pueden elegir entre tres métodos (estandarizado, basado en calificaciones internas básico y avanzado), proponiéndose incentivos para que avancen hacia la aplicación del método más avanzado (García y Salazar, 2005). 
Adicionalmente, se propone un tratamiento explícito a otros tipos de riesgos presentes en la actividad financiera, introduciendo el concepto del riesgo operativo como la pérdida resultante de los procesos realizados por el personal o sistemas internos inadecuados o defectuosos o afectados por acontecimientos externos; así como también el concepto de riesgo legal.

\section{- Método Estándar}

Bajo este método se establecen ponderaciones fijas según categorías establecidas, el riesgo es evaluado por empresas calificadoras de riesgo externas (ECAI) u organismos de crédito a la exportación (ECA) admitidos por el organismo supervisor. Este método incluye los lineamientos para que los supervisores puedan determinar la elegibilidad de una agencia de clasificación (García y Salazar, 2005).

- Métodos Basados en Calificaciones Internas (IRB)

Método introducido por el nuevo acuerdo. La principal diferencia entre el IRB y el método estándar radica en que las evaluaciones internas (de los principales factores de riesgo) de los bancos actúan como argumentos determinantes para el cálculo de la exigencia de capital mínimo (Superintencia de entidades financieras y cambiarias, 2003); sin embargo, el método no establece un cálculo para la determinación del capital mínimo. De acuerdo a lo descrito por (Muñoz, 2014) este nuevo enfoque se basa en los siguientes tres pilares:

i) Requerimiento mínimo de capital: Se toma en cuenta la calidad crediticia de los prestatarios (utilizando ratings externos o internos) y se adicionan requisitos de capital por el riesgo operacional. El riesgo de crédito ahora se calcula a través de tres componentes fundamentales:

$\checkmark$ PD (Probability of default) o probabilidad de incumplimiento.

$\checkmark$ LGD (Loss Given default) o pérdida dado el incumplimiento (también se conoce como "severidad", indicando la gravedad de la pérdida).

$\checkmark$ EAD (Exposure at default) o exposición en el momento del incumplimiento. 
ii) Proceso de supervisión bancaria: Los organismos supervisores y entidades reguladoras deberán estar capacitadas para incrementar el nivel de prudencia exigido a los bancos bajo su jurisdicción; además exige que la alta dirección del banco se involucre activamente en el control de riesgos y en la planificación futura de las necesidades de capital.

iii) Disciplina de mercado: Se establecen normas de transparencia y exige la publicación periódica de información acerca de su exposición a los diferentes riesgos y la suficiencia de sus fondos propios (I. Lopez, n.d.).

\section{BASILEA III}

Publicado en el 2010 se centra principalmente en el riesgo de "bank run" (pánico bancario), exigiendo diferentes niveles de capital para las distintas modalidades de depósitos bancarios y otros préstamos. Basilea III no sustituye, en su mayor parte, a las directrices ya conocidas como Basilea I y Basilea II, sino que las complementa (P. Lopez, 2011). Entre sus principales directrices propone:

- Aumentar sus reservas de capital, con la finalidad de protegerse de posibles caídas, introduciendo el concepto de "colchones o reservas de capital", que los bancos tendrán que constituir gradualmente entre los años 2016 y 2019, para que pudieran ser utilizados en futuros tiempos de crisis.

- Introduce el cálculo del "ratio de apalancamiento mínimo", ratio propuesto como medida complementaria a los ratios de solvencia.

- Introduce el cálculo de dos "ratios de liquidez": el LCR (Liquidity coverage ratio) y el NSFR (Net stable funding ratio).(Comité de Supervisión Bancaria de Basilea, 2014) 